\title{
REKOMENDASI OBJEK WISATA DI KABUPATEN HULU SUNGAI UTARA MENGGUNAKAN METODE PROFILE MATCHING
}

\author{
Muhammad Alkaff ${ }^{1}$, Nurul Fathanah Mustamin², Muhammad Reza Karimi ${ }^{3}$ \\ Program Studi Teknologi Informasi, Universitas Lambung Mangkurat ${ }^{1,2,3}$ \\ Email :m.alkaff@ulm.ac.id ${ }^{1}$, nurul.mustamin@ulm.ac.id², viperreza13@gmail.co.id ${ }^{3}$
}

\begin{abstract}
ABSTRAK
Kabupaten Hulu Sungai Utara (HSU) memiliki potensi wisata yang dapat meningkatkan pendapatan daerah. Tetapi, karena kurangnya informasi tentang objek-objek wisata yang ada di Kabupaten HSU sehingga banyak wisatawan belum mengetahui kriteria untuk menentukan objek wisata yang akan dikunjungi agar sesuai dengan ekspektasi. Sistem rekomendasi objek wisata merupakan salah satu solusi untuk mendukung keputusan wisatawan tersebut. Penggunaan metode profile matching digunakan untuk memberikan informasi serta rekomendasi objek wisata yang sesuai dengan kriteria calon wisatawan. Hasil penelitian menunjukkan sistem pemilihan objek wisata berdasarkan empat kriteria yaitu biaya, jenis, jarak, dan fasilitas dengan menggunakan profile matching bisa digunakan oleh para wisatawan, dibuktikan dengan pengujian sistem menggunakan Skala Likert dengan hasil analisa rata-rata Interpretasi Skor Perhitungan (ISP) yang mendapatkan nilai akurasi sebesar 93\%.
\end{abstract}

Kata Kunci: Hulu Sungai Utara, Sistem Pendukung Keputusan, Objek Wisata, Profile Matching

\section{ABSTRACT}

Hulu Sungai Utara Regency (HSU) has a large area, even wider than the Capital City of South Kalimantan, Banjarmasin. However, the regional income of the HSU Regency experienced a significant decrease when Balangan Regency separated itself by creating its own Regency due to the lack of natural resources contained in the HSU Regency. Even so, the HSU Regency still has natural resources in the field of tourism to increase regional income potential. Unfortunately, because of the lack of information about attractions in the District of HSU makes regional income in the tourism sector is not optimal. By making a recommendation system to support the decision to use the profile matching method and expected to provide information and recommendations on attractions that fit the criteria of potential tourists. Based on the results of system testing that has been done by means of an analysis of the average Interpretation Score Calculation (ISP) using a Likert scale obtained an accuracy value of $93 \%$.

Keywords: North Hulu Sungai, Decision Support System, Tourism Objects, Profile Matching.

\section{PENDAHULUAN}

Kabupaten Hulu Sungai Utara (HSU) mengalami penurunan pendapatan daerah semenjak Kabupaten Balangan memisahkan diri dari Kabupaten HSU pada tahun 2002. Pada saat Kabupaten Balangan masih menjadi bagian dari Kabupaten HSU, kabupaten ini memiliki angka pendapatan daerah sebesar 207.038,14 juta. Namun, pada tahun 2004, setelah Kabupaten Balangan yang kaya dengan sumber daya alamnya memisahkan diri dari 
Kabupaten HSU mengakibatkan angka pendapatan daerah Kabupaten HSU menurun hingga ke angka $138.716,76$ juta (Kementerian Keuangan, 2005).

Untuk mengatasi hal tersebut maka beberapa potensi pendapatan daerah di Kabupaten HSU perlu ditingkatkan, salah satunya potensi wisata. Menurut website resminya, Kabupaten Hulu Sungai Utara memiliki 25 objek wisata yang tersebar di berbagai Kecamatan mulai dari wisata alam, sejarah, kuliner, religi, dan lain-lain (Pemerintah Kabupaten Hulu Sungai Utara, 2019). Tetapi, karena tersebar diberbagai kecamatan serta kurangnya informasi tentang objek-objek wisata yang ada di website Kabupaten HSU, sehingga banyak wisatawan belum mengetahui kriteria untuk menentukan objek wisata yang akan dikunjungi agar sesuai dengan ekspektasi. Ada beberapa kriteria umum yang perlu di pertimbangkan dalam memilih tujuan objek wisata yaitu jarak, biaya, fasilitas, dan jenis wisata (Muhaimin et al., 2018).

Sistem pendukung keputusan (SPK) merupakan sistem yang memiliki kemampuan untuk menyelesaikan masalah yang bersifat semiterstuktur. Sistem ini merupakan sistem interaktif berbasis komputer, dengan mengumpulkan data atau model untuk menyelesaikan masalah tersebut. Namun, SPK hanya memberikan rekomendasi berdasarkan peringkat prioritas terbaik, dan keputusan itu akan dikembalikan kepada user (Afrianty \& Umbara, 2016; S et al., 2020). Kriteria umum pertimbangkan dalam memilih tujuan objek wisata dapat digunakan untuk memberikan rekomendasi kepada wisatawan dalam memilih tempat wisata berdasarkan preferensi diri sendiri. Metode yang dapat digunakan untuk membantu hal tersebut adalah metode pencocokan profil (profile matching). Konsep dari metode Profile matching adalah dengan mencari GAP berupa selisih nilai kompetensi pengunjung dengan kompetensi objek wisata.

Beberapa penelitian yang berhubungan dengan pemilihan objek wisata menggunakan Profile Matching telah dilakukan sebelumnya. Penelitian oleh Farid Al Muhaimin et al., dimana penelitian yang dilakukan bertujuan untuk membantu wisatawan dalam menentukan objek wisata sesuai kriteria seperti biaya, jenis wisata, jarak, dan fasilitas. Hasil penelitian ini didapatkan dari pengujian perbandingan kuesioner rekomendasi sistem dan hasil nilai akurasi sebesar 83\% (Muhaimin et al., 2018). Penelitian lain dilakukan oleh Widyanti Ramadani, et al., dimana peneliti membuat sebuah sistem untuk membantu para wisatawan mendapatkan informasi dan pengambilan keputusan dalam pemilihan obyek wisata secara efektif dan mampu membantu masyarakat untuk menetukan tempat objek wisata yang akan ditujunya. Sistem yang dibuat pada penelitian berdasarkan pada skala bobot yang dipilih oleh setiap wisatawan dalam pemilihan objek wisata dan juga sesuai kriteria nilai profile dari setiap objek wisata seperti faktor biaya, fasilitas pada objek wisata, jenis dari objek wisata, dan jarak tempuh menuju objek wisata. Hasil dari penelitian menunjukkan sistem yang dibuat telah sesuai dengan perhitungan dimana nilai tertinggi merupakan hasil peringkat untuk memperoleh pemilihan obyek wisata di Kabupaten Simalungun (Ramadani et al., 2019). Penelitian lain dilakukan oleh Galih Nur Faturochman, dimana peneliti menggunakan metode Profile Matching dalam menentukan pemilihan tempat wisata tirta yang sesuai dengan kriteria 
yang diinginkan wisatawan. Dalam penentuan pemilihan tempat wisata, ada beberapa kriteria yang menjadi dasar pengambilan keputusan antara lain harga, wahana, fasilitas, dan aksesibilitas. Adapun hasil akhir dalam penelitian ini adalah wisatawan dapat dengan mudah mengambil keputusan dengan melihat hasil yang sesuai dengan kriteria tempat wisata yang ingin dikunjungi (Faturochman, 2019).

Dari ketiga penelitian terkait, sistem yang dibuat masih berbasis web. Oleh karena itu, peneliti ingin membuat sistem rekomendasi untuk mendukung keputusan dalam pemilihan objek wisata di Kabupaten HSU berbasis Android untuk memudahkan user mengakses informasi. Android lebih diminati orang dan popular dibandingkan sistem operasi lainnya, dengan persentasi $82,8 \%$ dari permintaan pasar diseluruh dunia, dan $94 \%$ permintaan pasar untuk Indonesia (Alkaff et al., 2019). Selain itu, dari ketiga penelitian di atas untuk hasil akhir belum ada fitur untuk mengetahui letak visualisasi lokasi objek wisata. Oleh karena itu, pada penelitian ini, penulis akan melakukan pembuatan Sistem Penunjang Keputusan penentuan lokasi objek wisata menggunakan metode Profile Matching dengan menggunakan kritera jarak, biaya, fasilitas dan jenis wisata dan menerapkannya pada OS Android dengan menambahkan visualisasi letak lokasi objek wisata dengan Google Maps API untuk memudahkan pengguna mengetahui keberadaan objek wisata yang ada di Kabupaten HSU.

\section{LANDASAN TEORI}

\subsection{Sistem Pendukung Keputusan}

Sistem ini merupakan sistem interaktif berbasis komputer, yang bisa membantu dalam pengambilan keputusan dengan mengumpulkan data atau model untuk menyelesaikan masalah. Ada 3 unsur penting dalam konfigurasi SPK yaitu data manajemen, model managemen, dan user interface (Irianto, 2017).

\subsection{Metode Profile Matching}

Secara garis besar Profile Matching adalah sistem yang bekerja dengan membandingkan antara kompetensi pengunjung ke dalam kompetensi objek wisata sehingga bisa diketahui perbedaannya (juga bisa disebut gap), semakin kecil nilai gap itu maka semakin besar nilai bobot yang dihasilkan dan mendapat peluang prioritas paling atas untuk dipilih pengunjung, dan perhitungan berupa peringkat terbaik dengan menentukan Core Factor (CF) dan Secondary Factor (SF), lalu mengurutkan hasil ranking dengan prioritas terbaik dengan nilai bobot yang sudah ditentukan. Langkah perhitungan metode Profile Matching (Muhaimin et al., 2018):

a. Menghitung nilai gap, nilai gap itu di ambil dari nilai atribut (nilai kenyataannya) dikurang nilai target (nilai yang diinginkan)

gap = nilai atribut - nilai target

b. Melakukan pembobotan dengan hasil gap tersebut dan menentukan hasil selisih gap Berdasarkan tabel 1.

c. Menghitung Core Factor dan Secondary Factor, dengan menentukan aspek atau elemen mana yang menjadi Core Factor dan Secondary Factor. Rumus perhitungan:

Core Factor $N C F=\frac{\sum N C(i, s, p)}{\sum I C}$

Keterangan:

NCF : Nilai rata-rata $\mathrm{CF}$

$N C(i, s, p):$ Jumlah total nilai CF

IC : Jumlah item $\mathrm{CF}$

Secondary Factor $N S F=\frac{\sum N S(i, s, p)}{\sum I S}$ 
Keterangan:

NSF : Nilai rata-rata SF

$N S(i, s, p)$ : Jumlah total nilai SF

IS : Jumlah item SF

d. Setelah mendapatkan hasil rata-rata Core Factor dan Secondary Factor lalu menghitung nilai total setiap elemen dengan rumus:

$(x) \% . N C F(i, s, p)+(x) \% \cdot N S F(i, s, p)=$ $N S F(i, s, p)$

Keterangan:

$(x) \% \quad$ : Jumlah nilai berapa persen yang menjadi $\mathrm{CF}$ dan $\mathrm{SF}$

$N C F(i, s, p)$ : Nilai rata-rata $\mathrm{CF}$

$N S F(i, s, p)$ : Nilai rata-rata SF

$N(i, s, p) \quad$ : Nilai total dari aspek

e. Menghitung perankingan semua elemen, hasil akhir dari metode profile matching adalah perankingan prioritas terbaik dengan rumus:

$$
\text { Ranking }=\sum(x) \% . N k
$$

Keterangan:

$(x) \% \quad$ : Nilai Jumlah persen yang dimasukkan

Nk : Nilai Kriteria

Tabel 1. Pembobotan Nilai Gap

\begin{tabular}{|c|c|c|}
\hline $\begin{array}{l}\text { Selisih } \\
\text { Gap }\end{array}$ & $\begin{array}{l}\text { Bobot } \\
\text { Nilai }\end{array}$ & Keterangan \\
\hline 0 & 5 & Tidak ada selisih \\
\hline 1 & 4.5 & $\begin{array}{l}\text { Kompetensi kelebihan } \\
1 \text { tingkat }\end{array}$ \\
\hline-1 & 4 & $\begin{array}{l}\text { Kompetensi } \\
\text { kekurangan } 1 \text { tingkat }\end{array}$ \\
\hline 2 & 3.5 & $\begin{array}{l}\text { Kompetensi kelebihan } \\
2 \text { tingkat }\end{array}$ \\
\hline-2 & 3 & $\begin{array}{l}\text { Kompetensi } \\
\text { kekurangan } 2 \text { tingkat }\end{array}$ \\
\hline 3 & 2.5 & $\begin{array}{l}\text { Kompetensi kelebihan } \\
3 \text { tingkat }\end{array}$ \\
\hline-3 & 2 & $\begin{array}{l}\text { Kompetensi } \\
\text { kekurangan } 3 \text { tingkat }\end{array}$ \\
\hline 4 & 1.5 & $\begin{array}{l}\text { Kompetensi kelebihan } \\
4 \text { tingkat }\end{array}$ \\
\hline-4 & 1 & $\begin{array}{l}\text { Kompetensi } \\
\text { kekurangan } 4 \text { tingkat }\end{array}$ \\
\hline
\end{tabular}

\subsection{Android}

Android menyediakan platform terbuka untuk para pengembang agar dapat membuat aplikasi mereka sendiri. Lalu untuk mengembangkan sebuah Android, dibuatlah Open Handset Alliance, konsorsium dari 34 perusahaan peranti lunak, peranti keras, dan telekomunikasi, termasuk Nvidia, Google, Intel, HTC, Motorola, T-Mobile, dan Qualcomm (Alkaff et al., 2019).

\section{METODE PENELITIAN}

3.1. Data Penelitian

Data penelitian yang digunakan sebagai berikut:

a. Objek wisata di Kabupaten HSU yang terdata di situs resmi pemerintah Kabupaten HSU (Badan Pusat Statistik Kabupaten Hulu Sungai Utara, 2016).

b. Kuisioner untuk menentukan Core Factor dan Secondary Factor.

c. Kriteria SPK dalam menentukan rekomendasi objek wisata di Kabupaten HSU yaitu Jarak wisata, Biaya wisata, Fasilitas wisata, Jenis wisata.

\subsection{Alat Penelitian}

Adapun perangkat keras yang digunakan adalah:

a. Laptop, dengan spesifikasi Core i5, RAM 8GB.

b. Processor dengan kecepatan 2.7 Ghz.

c. Koneksi dengan jaringan internet.

d. Kamera Smartphone OPPO F9.

Perangkat lunak yang digunakan:

1. Operating System Windows 10

2. Android Studio

3. Sublime Text 3.2.2

4. Google Maps API

5. Bahasa Pemrograman Java dan PHP

6. Database MariaDB 


\subsection{Metode Pengembangan Sistem}

Metode penelitian ini memakai metode waterfall. Berikut gambaran tahapan metode waterfall yang dapat dilihat pada Gambar 1 (Dennis et al., 2012) dibawah ini.

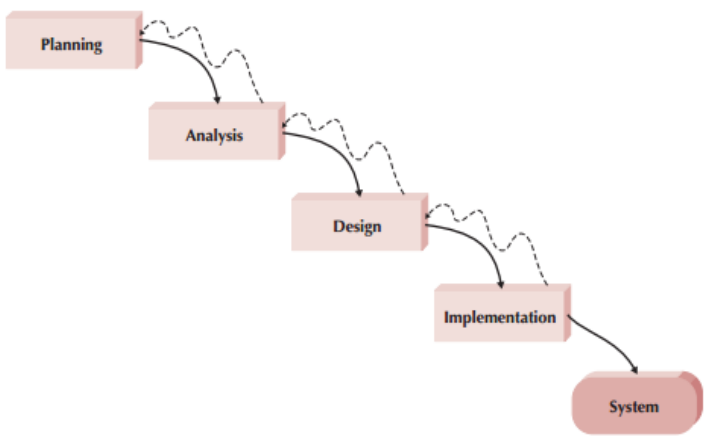

Gambar 1. Tahapan Metode Waterfall

\subsection{Perancangan Sistem}

Dalam perancangan alur sistem yang akan dibuat dapat dilihat pada Gambar 2 sebagai berikut:

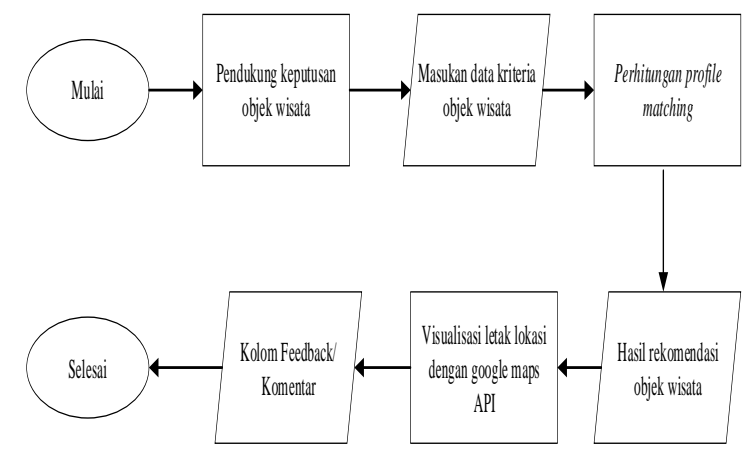

Gambar 2. Alur Perancangan Sistem

\subsection{Metode Pengumpulan Data}

Metode pengumpulan data memerlukan teknik atau cara agar mempermudah dalam melakukan penelitian yaitu:
a. Studi pustaka
b. Kuisioner, dan
c. Observasi.

\subsection{Proses Kerja Metode Profile Matching}

Adapun rangkaian proses sistem menggunakan profile matching :

a. Mengumpulkan beberapa data objek wisata di Kabupaten HSU yang nanti akan menjadi data alternatif objek wisata yang dapat dikunjungi.

b. Menentukan parameter kriteria yang akan menjadi acuan dalam pengambilan keputusan dalam menentukan rekomendasi objek wisata.

c. Menentukan nilai atau rating kecocokan pada setiap kriteria.

d. Membuat tabel pembobotan gap.

e. Menghitung selisih nilai gap yang didapat dari hasil pengurangan nilai profile objek wisata dengan nilai target atau nilai bobot yang dipilih pengunjung.

f. Melakukan pembobotan nilai berdasarkan hasil gap.

g. Menentukan kriteria apa yang masuk ke dalam kategoti core factor dan mana yang masuk kategori secondary factor.

h. Menghitung nilai rata-rata core factor dan nilai secondary factor.

i. Setelah mendapatkan hasil rata-rata core factor dan secondary factor lalu menghitung nilai total setiap elemen.

j. Mengurutkan hasil nilai dari yang terbesar sebagai ranking rekomendasi objek wisata di Kabupaten HSU.

\subsection{Skenario Pengujian}

Terdapat dua skenario pengujian yang dilakukan yaitu, pengujian validitas data dan pengujian sistem.

a. Skenario pengujian kuisioner untuk memastikan validitas data kuisioner akan digunakan metode pengujian validitas dengan software SPSS.

b. Skenario pengujian sistem akan menggunakan kuisioner kepada pengunjung objek wisata atau masyarakat. Hasil dari pengujian melalui kuisioner tersebut dijadikan pembanding dengan output rekomendasi objek wisata di Kabupaten HSU. 


\section{HASIL DAN PEMBAHASAN}

Dalam sistem ini terdapat 25 objek wisata di Kabupaten HSU sebagai data alternatif. Kriteria objek wisata yang digunakan untuk membantu calon pengunjung dalam pengambilan keputusan adalah biaya, jenis wisata, jarak, fasilitas. Setiap kriteria memiliki rating kecocokan mulai dari skala 1 sampai dengan skala 5 tergantung tingkat kepentingannya. Berikut ini rating kecocokan masing-masing kriteria yaitu:

Tabel 2. Rating Kecocokan Kriteria

\begin{tabular}{|c|c|c|}
\hline Kriteria & Nilai & Skala \\
\hline \multirow{5}{*}{ Biaya } & $\begin{array}{l}\text { Kurang Dari Rp. } \\
6.000\end{array}$ & 1 \\
\hline & $\begin{array}{l}\text { Rp. } 7.000 \text { s/d Rp. } \\
12.000\end{array}$ & 2 \\
\hline & $\begin{array}{l}\text { Rp. } 13.000 \text { s/d Rp. } \\
18.000\end{array}$ & 3 \\
\hline & $\begin{array}{l}\text { Rp. } 19.000 \text { s/d Rp. } \\
24.000\end{array}$ & 4 \\
\hline & $\begin{array}{l}\text { Lebih Dari Rp. } \\
25.000\end{array}$ & 5 \\
\hline \multirow{5}{*}{$\begin{array}{l}\text { Jenis } \\
\text { Wisata }\end{array}$} & Wisata Alam & 1 \\
\hline & Wisata Keluarga & 2 \\
\hline & Wisata Sejarah & 3 \\
\hline & $\begin{array}{l}\text { Wisata Kuliner, } \\
\text { Kerajinan }\end{array}$ & 4 \\
\hline & Wisata Religi & 5 \\
\hline \multirow{5}{*}{ Jarak } & Kurang Dari 8km & 1 \\
\hline & $9 \mathrm{~km} \mathrm{~s} / \mathrm{d} 17 \mathrm{~km}$ & 2 \\
\hline & $18 \mathrm{~km} \mathrm{~s} / \mathrm{d} 26 \mathrm{~km}$ & 3 \\
\hline & $27 \mathrm{~km} \mathrm{~s} / \mathrm{d} 35 \mathrm{~km}$ & 4 \\
\hline & Lebih Dari 36km & 5 \\
\hline \multirow{5}{*}{ Fasilitas } & $\begin{array}{l}\text { WC, Tempat Duduk, } \\
\text { Tempat Belanja }\end{array}$ & 1 \\
\hline & WC, Tempat Duduk & 2 \\
\hline & Tempat Duduk & 3 \\
\hline & $\mathrm{WC}$ & 4 \\
\hline & Tidak Ada Fasilitas & 5 \\
\hline
\end{tabular}

Langkah selanjutnya yaitu mencocokan data alternatif objek wisata beserta nilai berdasarkan masing-masing kriteria (biaya, jenis wisata, jarak, fasilitas) sebagai berikut:

Tabel 3. Kecocokan Data Alternatif

\begin{tabular}{|c|c|c|c|c|c|}
\hline No & $\begin{array}{l}\text { Objek } \\
\text { Wisata }\end{array}$ & Biaya & $\begin{array}{c}\text { Jen } \\
\text { is } \\
\text { Wi } \\
\text { sat } \\
\text { a }\end{array}$ & $\begin{array}{c}\mathrm{Ja} \\
\mathrm{ra} \\
\mathrm{k}\end{array}$ & $\begin{array}{c}\mathrm{Fa} \\
\text { sil } \\
\text { ita } \\
\mathrm{s}\end{array}$ \\
\hline 1. & $\begin{array}{l}\text { Mesjid jami } \\
\text { sungai banar }\end{array}$ & 1 & 5 & 1 & 4 \\
\hline 2. & $\begin{array}{l}\text { Pusat } \\
\text { Kerajinan } \\
\text { Tikar, } \\
\text { Purun, } \\
\text { Rotan, dan } \\
\text { Ilung }\end{array}$ & 1 & 4 & 1 & 5 \\
\hline 3 & Itik Alabio & 1 & 1 & 1 & 5 \\
\hline 4. & $\begin{array}{l}\text { Candi } \\
\text { Agung }\end{array}$ & 2 & 3 & 1 & 1 \\
\hline 5. & $\begin{array}{l}\text { Kolam } \\
\text { Renang } \\
\text { Tirta Agung } \\
\text { Suryanata }\end{array}$ & 1 & 2 & 1 & 4 \\
\hline 6. & $\begin{array}{l}\text { Danau } \\
\text { Cermin } \\
\end{array}$ & 1 & 1 & 2 & 3 \\
\hline 7. & $\begin{array}{l}\text { Melati } \\
\text { Waterboom }\end{array}$ & 5 & 2 & 1 & 1 \\
\hline 8. & $\begin{array}{l}\text { Mesjid Raya } \\
\text { At-taqwa }\end{array}$ & 1 & 5 & 1 & 4 \\
\hline 9. & $\begin{array}{l}\text { Monumen } \\
\text { Itik Alabio }\end{array}$ & 1 & 3 & 1 & 1 \\
\hline 10. & $\begin{array}{l}\text { Monumen } \\
\text { Perjuangan } \\
\text { Rakyat HSU }\end{array}$ & 1 & 3 & 1 & 5 \\
\hline 11. & $\begin{array}{l}\text { Pasar Subuh } \\
\text { Kerajinan } \\
\text { Anyaman }\end{array}$ & 1 & 4 & 1 & 5 \\
\hline 12. & Hutan Kota & 1 & 1 & 1 & 5 \\
\hline 13. & Pasar Wadai & 1 & 4 & 1 & 1 \\
\hline 14. & $\begin{array}{l}\text { Taman Putri } \\
\text { Junjung } \\
\text { Buih }\end{array}$ & 1 & 2 & 1 & 1 \\
\hline 15. & $\begin{array}{l}\text { Siring } \\
\text { Patung itik }\end{array}$ & 1 & 2 & 1 & 1 \\
\hline & $\begin{array}{l}\text { Siring Pasar } \\
\text { Modern }\end{array}$ & 1 & 2 & 1 & 1 \\
\hline
\end{tabular}




\begin{tabular}{|c|c|c|c|c|c|}
\hline 17. & $\begin{array}{l}\text { Danau Biru } \\
\text { Tabur }\end{array}$ & 2 & 1 & 2 & 1 \\
\hline 18. & $\begin{array}{l}\text { Makam } \\
\text { Datu } \\
\text { Sulaiman }\end{array}$ & 1 & 5 & 1 & 4 \\
\hline 19. & $\begin{array}{l}\text { Lapangan } \\
\text { Golf air } \\
\text { tawar }\end{array}$ & 1 & 2 & 2 & 3 \\
\hline 20. & $\begin{array}{l}\text { Makam } \\
\text { Pahlawan } \\
\text { Tabur }\end{array}$ & 1 & 3 & 2 & 5 \\
\hline 21. & $\begin{array}{l}\text { Mesjid } \\
\text { Siratul } \\
\text { Ummah }\end{array}$ & 1 & 5 & 3 & 4 \\
\hline 22. & $\begin{array}{l}\text { Budidaya } \\
\text { Kerbau } \\
\text { Rawa }\end{array}$ & 5 & 1 & 3 & 5 \\
\hline 23. & $\begin{array}{l}\text { Danau } \\
\text { Tampakang }\end{array}$ & 5 & 1 & 3 & 5 \\
\hline 24. & $\begin{array}{l}\text { Dermaga } \\
\text { Paminggir }\end{array}$ & 5 & 2 & 5 & 2 \\
\hline 25. & $\begin{array}{l}\text { Mesjid } \\
\text { Besar }\end{array}$ & 1 & 5 & 2 & 4 \\
\hline
\end{tabular}

\begin{tabular}{clllll}
\hline 3 & $\begin{array}{l}\text { Itik } \\
\text { Alabio }\end{array}$ & 1 & 1 & 1 & 5 \\
\hline 4. & $\begin{array}{l}\text { Candi } \\
\text { Agung }\end{array}$ & 2 & 3 & 1 & 1 \\
\hline Kolam \\
Renang \\
Tirta \\
5. \\
$\begin{array}{l}\text { Agung } \\
\text { Suryanat } \\
\text { a }\end{array}$ & 1 & 2 & 1 & 4 \\
\end{tabular}

\begin{tabular}{|c|c|c|c|c|c|}
\hline 6. & $\begin{array}{l}\text { Danau } \\
\text { Cermin }\end{array}$ & 1 & 1 & 2 & 3 \\
\hline 7. & $\begin{array}{l}\text { Melati } \\
\text { Waterbo }\end{array}$ & 5 & 2 & 1 & 1 \\
\hline
\end{tabular}

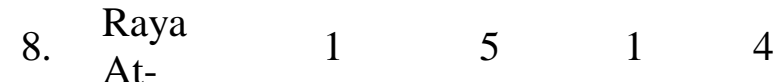
taqwa Monum

$\begin{array}{llllll}\text { 9. en Itik } & 1 & 3 & 1 & 1\end{array}$
Alabio Monum en

Selanjutnya mencari nilai gap dari masing-masing data alternatif (nilai profile objek wisata) yang dikurang nilai target sesuai keinginan calon pengunjung berdasarkan rumus (1) dengan hasil sebagai berikut:

$\begin{array}{llllll}\text { 10. } \begin{array}{l}\text { Perjuang } \\ \text { an }\end{array} & 1 & 3 & 1 & 5 \\ \text { Rakyat } & & & & & \\ \text { HSU } & & & & & \end{array}$

Pasar Subuh

11. $\begin{array}{lllll}\text { Kerajina } & 1 & 4 & 1 & 5\end{array}$
Anyama

Tabel 4. Hasil Gap

\begin{tabular}{|c|c|c|c|c|c|c|c|c|c|c|c|}
\hline \multirow{2}{*}{$\begin{array}{c}\text { No } \\
\text {. }\end{array}$} & \multirow{2}{*}{$\begin{array}{c}\text { Objek } \\
\text { Wisata }\end{array}$} & \multirow{2}{*}{$\begin{array}{c}\text { Biay } \\
\text { a }\end{array}$} & \multirow{2}{*}{$\begin{array}{c}\text { Jenis } \\
\text { Wisat } \\
\text { a } \\
\end{array}$} & \multirow{2}{*}{ Jarak } & $\begin{array}{c}\text { Fasilit } \\
\text { as }\end{array}$ & 12. & $\begin{array}{l}\text { Hutan } \\
\text { Kota }\end{array}$ & 1 & 1 & 1 & 5 \\
\hline & & & & & & 13. & $\begin{array}{l}\text { Pasar } \\
\text { Wadai }\end{array}$ & 1 & 4 & 1 & 1 \\
\hline 1. & $\begin{array}{l}\text { Mesjid } \\
\text { jami } \\
\text { sungai } \\
\text { banar }\end{array}$ & 1 & 5 & 1 & 4 & 14. & $\begin{array}{l}\text { Taman } \\
\text { Putri } \\
\text { Junjung }\end{array}$ & 1 & 2 & 1 & 1 \\
\hline \multirow[t]{2}{*}{2.} & \multirow{2}{*}{$\begin{array}{l}\text { Pusat } \\
\text { Kerajina } \\
\text { n Tikar, } \\
\text { Purun, } \\
\text { Rotan, } \\
\text { dan } \\
\text { Ilung }\end{array}$} & \multirow[t]{2}{*}{1} & \multirow[t]{2}{*}{4} & \multirow[t]{2}{*}{1} & \multirow[t]{2}{*}{5} & 15. & $\begin{array}{l}\text { Buih } \\
\text { Siring } \\
\text { Patung } \\
\text { itik } \\
\end{array}$ & 1 & 2 & 1 & 1 \\
\hline & & & & & & 16. & $\begin{array}{l}\text { Siring } \\
\text { Pasar } \\
\text { Modern }\end{array}$ & 1 & 2 & 1 & 1 \\
\hline
\end{tabular}




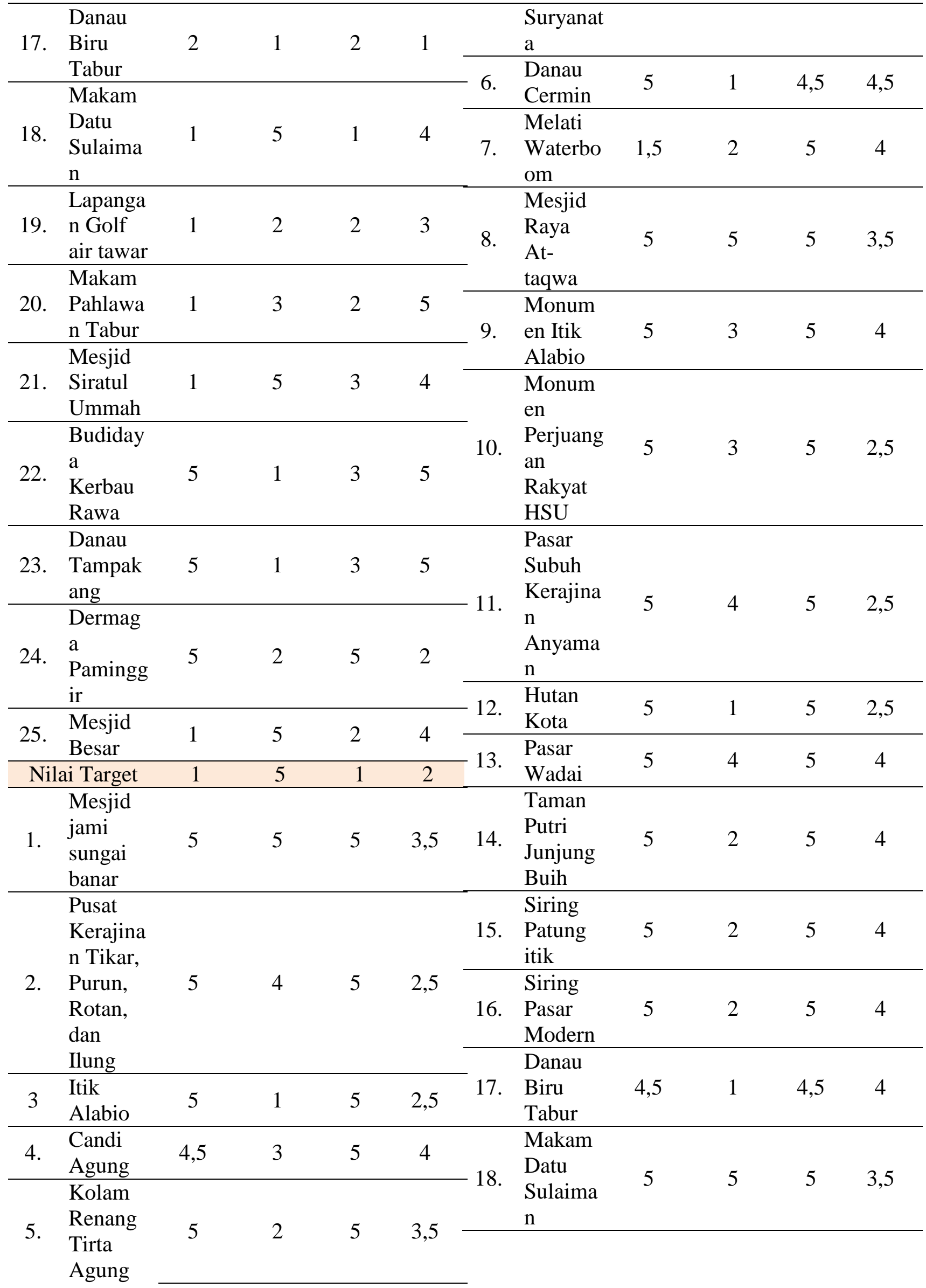




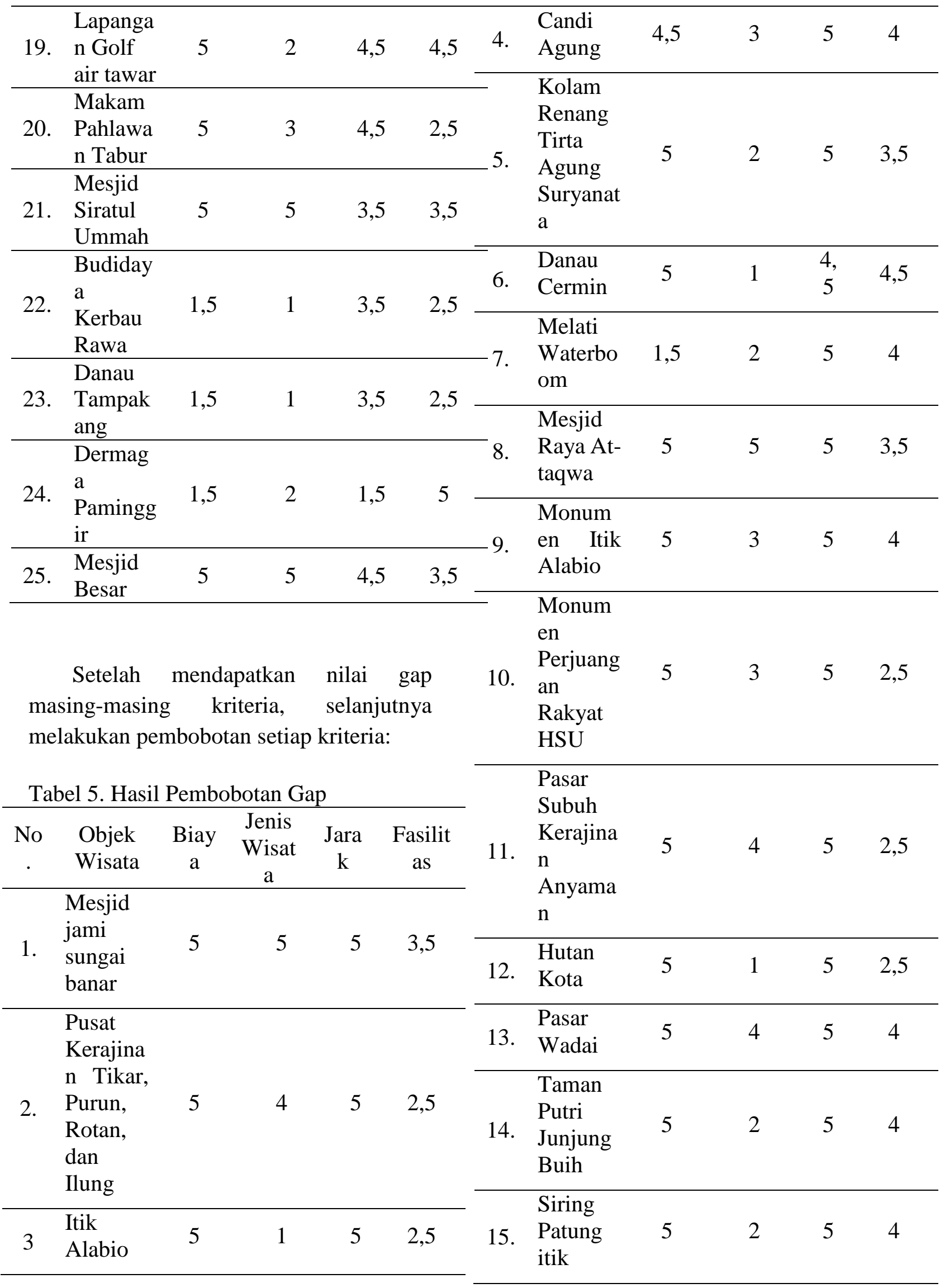




\begin{tabular}{|c|c|c|c|c|c|c|c|c|c|c|}
\hline \multirow[b]{2}{*}{16.} & \multirow{2}{*}{$\begin{array}{l}\text { Siring } \\
\text { Pasar } \\
\text { Modern }\end{array}$} & \multirow[b]{2}{*}{5} & \multirow[b]{2}{*}{2} & \multirow[b]{2}{*}{5} & \multirow[b]{2}{*}{4} & \multicolumn{3}{|c|}{ Tabel 6. Core Factor } & \multirow{2}{*}{$\begin{array}{l}\text { Jenis } \\
\text { Wisat } \\
\text { a } \\
\end{array}$} & \multirow[b]{2}{*}{$\begin{array}{c}\text { Perhitunga } \\
\mathrm{n}\end{array}$} \\
\hline & & & & & & No. & $\begin{array}{l}\text { Objek } \\
\text { Wisata }\end{array}$ & $\begin{array}{c}\text { Biay } \\
\text { a }\end{array}$ & & \\
\hline 17. & $\begin{array}{l}\text { Danau } \\
\text { Biru } \\
\text { Tabur }\end{array}$ & 4,5 & 1 & 4,5 & 4 & \multirow[t]{2}{*}{1.} & \multirow{2}{*}{$\begin{array}{l}\text { Mesjid } \\
\text { jami } \\
\text { sungai } \\
\text { banar }\end{array}$} & \multirow[t]{2}{*}{5} & \multirow[t]{2}{*}{5} & \multirow[t]{2}{*}{5} \\
\hline & Makam & & & & & & & & & \\
\hline 18. & Sulaima & 5 & 5 & 5 & 3,5 & & $\begin{array}{l}\text { Pusat } \\
\text { Kerajinan } \\
\text { Tikar. }\end{array}$ & & \multirow{2}{*}{4} & \multirow{2}{*}{4,5} \\
\hline 19. & $\begin{array}{l}\text { Lapanga } \\
\text { n Golf } \\
\text { air tawar }\end{array}$ & 5 & 2 & $\begin{array}{l}4, \\
5\end{array}$ & 4,5 & 2. & $\begin{array}{l}\text { Purun, } \\
\text { Rotan, } \\
\text { dan Ilung }\end{array}$ & 5 & & \\
\hline 20. & $\begin{array}{l}\text { Makam } \\
\text { Pahlawa } \\
\text { n Tabur }\end{array}$ & 5 & 3 & $\begin{array}{l}4, \\
5\end{array}$ & 2,5 & 3 & $\begin{array}{l}\text { Itik } \\
\text { Alabio }\end{array}$ & 5 & 1 & 3 \\
\hline \multirow{2}{*}{21.} & Mesjid & \multirow{2}{*}{5} & \multirow{2}{*}{5} & \multirow{2}{*}{$\begin{array}{l}3, \\
5\end{array}$} & \multirow{2}{*}{3,5} & 4. & $\begin{array}{l}\text { Candi } \\
\text { Agung }\end{array}$ & 4,5 & 3 & 3,75 \\
\hline & Ummah & & & & & & $\begin{array}{l}\text { Kolam } \\
\text { Renang }\end{array}$ & & & \\
\hline 22. & $\begin{array}{l}\text { Budiday } \\
\text { a Kerbau } \\
\text { Rawa }\end{array}$ & 1,5 & 1 & $\begin{array}{l}3, \\
5\end{array}$ & 2,5 & 5. & $\begin{array}{l}\text { Tirta } \\
\text { Agung } \\
\text { Suryanat }\end{array}$ & 5 & 2 & 3,5 \\
\hline & Danau & & & & & & $\mathrm{a}$ & & & \\
\hline 23. & $\begin{array}{l}\text { Tampak } \\
\text { ang }\end{array}$ & 1,5 & 1 & 5 & 2,5 & 6. & $\begin{array}{l}\text { Danau } \\
\text { Cermin }\end{array}$ & 5 & 1 & 3 \\
\hline 24. & $\begin{array}{l}\text { Dermag } \\
\text { a } \\
\text { Pamingg }\end{array}$ & 1,5 & 2 & $\begin{array}{l}1, \\
5\end{array}$ & 5 & 7. & $\begin{array}{l}\text { Melati } \\
\text { Waterboo } \\
\mathrm{m}\end{array}$ & 1,5 & 2 & 1,75 \\
\hline 25. & $\begin{array}{l}\text { Mesjid } \\
\text { Besar }\end{array}$ & 5 & 5 & $\begin{array}{l}4, \\
5\end{array}$ & 3,5 & 8. & $\begin{array}{l}\text { Mesjid } \\
\text { Raya At- } \\
\text { taqwa }\end{array}$ & 5 & 5 & 5 \\
\hline & Selanjutn & $\mathrm{a}$ me & & eria & ana & 9. & $\begin{array}{l}\text { Monume } \\
\text { n Itik } \\
\text { Alabio }\end{array}$ & 5 & 3 & 4 \\
\hline $\begin{array}{l}\text { ya } \\
\text { da } \\
\text { jen } \\
\text { de } \\
\text { fac } \\
\text { ma }\end{array}$ & $\begin{array}{l}\text { g masuk } \\
\text { secondar } \\
\text { is wisata } \mathrm{m} \\
\text { igan fasili } \\
\text { tor. Sete } \\
\text { sing-masin }\end{array}$ & $\begin{array}{l}\text { dal } \\
\text { fact } \\
\text { suk } \\
\text { s } \mathrm{m} \\
\text { h i }\end{array}$ & & $\begin{array}{l}\text { ore } \\
\text { a d } \\
\text { ctor }\end{array}$ & $\begin{array}{l}\text { tor } \\
\text { gan } \\
\text { rak } \\
\text { ary } \\
\text { ilai } \\
\text { kan }\end{array}$ & 10. & $\begin{array}{l}\text { Monume } \\
\mathrm{n} \\
\text { Perjuang } \\
\text { an } \\
\text { Rakyat } \\
\text { HSU }\end{array}$ & 5 & 3 & 4 \\
\hline $\begin{array}{l}\mathrm{ba} \\
\mathrm{sel}\end{array}$ & $\begin{array}{l}\text { giannya be } \\
\text { agai berikı }\end{array}$ & lasar & & $\mathrm{d}$ & (3) & 11. & $\begin{array}{l}\text { Pasar } \\
\text { Subuh }\end{array}$ & 5 & 4 & 4,5 \\
\hline
\end{tabular}




\begin{tabular}{|c|c|c|c|c|}
\hline & $\begin{array}{l}\text { Kerajinan } \\
\text { Anyaman }\end{array}$ & & & \\
\hline 12. & $\begin{array}{l}\text { Hutan } \\
\text { Kota }\end{array}$ & 5 & 1 & 3 \\
\hline 13. & $\begin{array}{l}\text { Pasar } \\
\text { Wadai }\end{array}$ & 5 & 4 & 4,5 \\
\hline 14. & $\begin{array}{l}\text { Taman } \\
\text { Putri } \\
\text { Junjung } \\
\text { Buih }\end{array}$ & 5 & 2 & 3,5 \\
\hline 15. & $\begin{array}{l}\text { Siring } \\
\text { Patung } \\
\text { itik }\end{array}$ & 5 & 2 & 3,5 \\
\hline 16. & $\begin{array}{l}\text { Siring } \\
\text { Pasar } \\
\text { Modern }\end{array}$ & 5 & 2 & 3,5 \\
\hline 17. & $\begin{array}{l}\text { Danau } \\
\text { Biru } \\
\text { Tabur }\end{array}$ & 4,5 & 1 & 2,75 \\
\hline 18. & $\begin{array}{l}\text { Makam } \\
\text { Datu } \\
\text { Sulaiman }\end{array}$ & 5 & 5 & 5 \\
\hline 19. & $\begin{array}{l}\text { Lapangan } \\
\text { Golf air } \\
\text { tawar }\end{array}$ & 5 & 2 & 3,5 \\
\hline 20 . & $\begin{array}{l}\text { Makam } \\
\text { Pahlawan } \\
\text { Tabur }\end{array}$ & 5 & 3 & 4 \\
\hline 21. & $\begin{array}{l}\text { Mesjid } \\
\text { Siratul } \\
\text { Ummah }\end{array}$ & 5 & 5 & 5 \\
\hline 22. & $\begin{array}{l}\text { Budidaya } \\
\text { Kerbau } \\
\text { Rawa }\end{array}$ & 1,5 & 1 & 1,25 \\
\hline 23. & $\begin{array}{l}\text { Danau } \\
\text { Tampaka } \\
\text { ng }\end{array}$ & 1,5 & 1 & 1,25 \\
\hline 24. & $\begin{array}{l}\text { Dermaga } \\
\text { Paminggi } \\
\mathrm{r}\end{array}$ & 1,5 & 2 & 1,75 \\
\hline 25. & $\begin{array}{l}\text { Mesjid } \\
\text { Besar }\end{array}$ & 5 & 5 & 5 \\
\hline
\end{tabular}

\begin{tabular}{ll}
\hline $\begin{array}{c}\text { Ite } \\
\mathrm{m}\end{array}$ & 2 \\
\hline
\end{tabular}

Tabel 6. Secondary Factor

\begin{tabular}{|c|c|c|c|c|}
\hline No. & $\begin{array}{c}\text { Objek } \\
\text { Wisata }\end{array}$ & $\begin{array}{c}\text { Jara } \\
\mathrm{k}\end{array}$ & $\begin{array}{c}\text { Fasilit } \\
\text { as }\end{array}$ & $\begin{array}{c}\text { Perhitunga } \\
n\end{array}$ \\
\hline 1. & $\begin{array}{l}\text { Mesjid } \\
\text { jami } \\
\text { sungai } \\
\text { banar }\end{array}$ & 5 & 3,5 & 4,25 \\
\hline
\end{tabular}

\begin{tabular}{l}
\hline Pusat \\
Kerajinan
\end{tabular}

$\begin{array}{llll}\text { 2. Tikar, } & 5 & 2,5 & 3,75\end{array}$

Rotan, dan Ilung

\begin{tabular}{clccc}
\hline 3 & $\begin{array}{l}\text { Itik } \\
\text { Alabio }\end{array}$ & 5 & 2,5 & 3,75 \\
\hline 4. & $\begin{array}{l}\text { Candi } \\
\text { Agung }\end{array}$ & 5 & 4 & 4,5 \\
\hline
\end{tabular}

Kolam

Renang

5. $\begin{array}{llll}\text { Tirta } & & & \\ \text { Agung } & 5 & 3,5 & 4,25\end{array}$

Suryanat a

\begin{tabular}{|c|c|c|c|c|}
\hline 6. & $\begin{array}{l}\text { Danau } \\
\text { Cermin }\end{array}$ & 4,5 & 4,5 & 4,5 \\
\hline 7. & $\begin{array}{l}\text { Melati } \\
\text { Waterboo } \\
\mathrm{m}\end{array}$ & 5 & 4 & 4,5 \\
\hline 8. & $\begin{array}{l}\text { Mesjid } \\
\text { Raya At- } \\
\text { taqwa }\end{array}$ & 5 & 3,5 & 4,25 \\
\hline 9. & $\begin{array}{l}\text { Monume } \\
\text { n Itik } \\
\text { Alabio }\end{array}$ & 5 & 4 & 4,5 \\
\hline 10. & $\begin{array}{l}\text { Monume } \\
\mathrm{n} \\
\text { Perjuang } \\
\text { an }\end{array}$ & 5 & 2,5 & 3,75 \\
\hline
\end{tabular}




\begin{tabular}{|c|c|c|c|c|}
\hline & $\begin{array}{l}\text { Rakyat } \\
\text { HSU }\end{array}$ & & & \\
\hline 11. & $\begin{array}{l}\text { Pasar } \\
\text { Subuh } \\
\text { Kerajinan } \\
\text { Anyaman }\end{array}$ & 5 & 2,5 & 3,75 \\
\hline 12. & $\begin{array}{l}\text { Hutan } \\
\text { Kota }\end{array}$ & 5 & 2,5 & 3,75 \\
\hline 13. & $\begin{array}{l}\text { Pasar } \\
\text { Wadai }\end{array}$ & 5 & 4 & 4,5 \\
\hline 14. & $\begin{array}{l}\text { Taman } \\
\text { Putri } \\
\text { Junjung } \\
\text { Buih }\end{array}$ & 5 & 4 & 4,5 \\
\hline 15. & $\begin{array}{l}\text { Siring } \\
\text { Patung } \\
\text { itik }\end{array}$ & 5 & 4 & 4,5 \\
\hline 16. & $\begin{array}{l}\text { Siring } \\
\text { Pasar } \\
\text { Modern }\end{array}$ & 5 & 4 & 4,5 \\
\hline 17. & $\begin{array}{l}\text { Danau } \\
\text { Biru } \\
\text { Tabur }\end{array}$ & 4,5 & 4 & 4,25 \\
\hline 18. & $\begin{array}{l}\text { Makam } \\
\text { Datu } \\
\text { Sulaiman }\end{array}$ & 5 & 3,5 & 4,25 \\
\hline 19. & $\begin{array}{l}\text { Lapangan } \\
\text { Golf air } \\
\text { tawar }\end{array}$ & 4,5 & 4,5 & 4,5 \\
\hline 20. & $\begin{array}{l}\text { Makam } \\
\text { Pahlawan } \\
\text { Tabur }\end{array}$ & 4,5 & 2,5 & 3,5 \\
\hline 21. & $\begin{array}{l}\text { Mesjid } \\
\text { Siratul } \\
\text { Ummah }\end{array}$ & 3,5 & 3,5 & 3,5 \\
\hline 22. & $\begin{array}{l}\text { Budidaya } \\
\text { Kerbau } \\
\text { Rawa }\end{array}$ & 3,5 & 2,5 & 3 \\
\hline 23. & $\begin{array}{l}\text { Danau } \\
\text { Tampaka } \\
\text { ng }\end{array}$ & 3,5 & 2,5 & 3 \\
\hline
\end{tabular}

\begin{tabular}{clccc}
\hline 24. & $\begin{array}{l}\text { Dermaga } \\
\text { Paminggi } \\
\mathrm{r}\end{array}$ & 1,5 & 5 & 3,25 \\
\hline 25. & $\begin{array}{l}\text { Mesjid } \\
\text { Besar }\end{array}$ & 4,5 & 3,5 & 4 \\
\hline $\begin{array}{c}\text { Ite } \\
\mathrm{m}\end{array}$ & & 2 & \\
\hline
\end{tabular}

Setelah mendapatkan nilai core factor dan secondary factor, lalu nilai core factor dan secondary factor dihitung lagi untuk mendapatkan nilai total aspek berdasarkan rumus (4) sebagai berikut:

Tabel 7. Nilai Total Aspek

\begin{tabular}{|c|c|c|c|c|}
\hline No. & $\begin{array}{c}\text { Objek } \\
\text { Wisata }\end{array}$ & Core & $\begin{array}{c}\text { Seconda } \\
r y\end{array}$ & Total \\
\hline 1. & $\begin{array}{l}\text { Mesjid } \\
\text { jami } \\
\text { sungai } \\
\text { banar }\end{array}$ & 5 & 4,25 & $\begin{array}{c}4,92 \\
5\end{array}$ \\
\hline 2. & $\begin{array}{l}\text { Pusat } \\
\text { Kerajinan } \\
\text { Tikar, } \\
\text { Purun, } \\
\text { Rotan, } \\
\text { dan Ilung }\end{array}$ & 4,5 & 3,75 & $\begin{array}{c}4,42 \\
5\end{array}$ \\
\hline 3 & $\begin{array}{l}\text { Itik } \\
\text { Alabio }\end{array}$ & 3 & 3,75 & $\begin{array}{c}3,07 \\
5\end{array}$ \\
\hline 4. & $\begin{array}{l}\text { Candi } \\
\text { Agung }\end{array}$ & 3,75 & 4,5 & $\begin{array}{c}3,82 \\
5\end{array}$ \\
\hline 5. & $\begin{array}{l}\text { Kolam } \\
\text { Renang } \\
\text { Tirta } \\
\text { Agung } \\
\text { Suryanat } \\
\text { a }\end{array}$ & 3,5 & 4,25 & $\begin{array}{c}3,57 \\
5\end{array}$ \\
\hline 6. & $\begin{array}{l}\text { Danau } \\
\text { Cermin }\end{array}$ & 3 & 4,5 & 3,15 \\
\hline 7. & $\begin{array}{l}\text { Melati } \\
\text { Waterboo } \\
\text { m }\end{array}$ & 1,75 & 4,5 & $\begin{array}{c}2,02 \\
5\end{array}$ \\
\hline
\end{tabular}




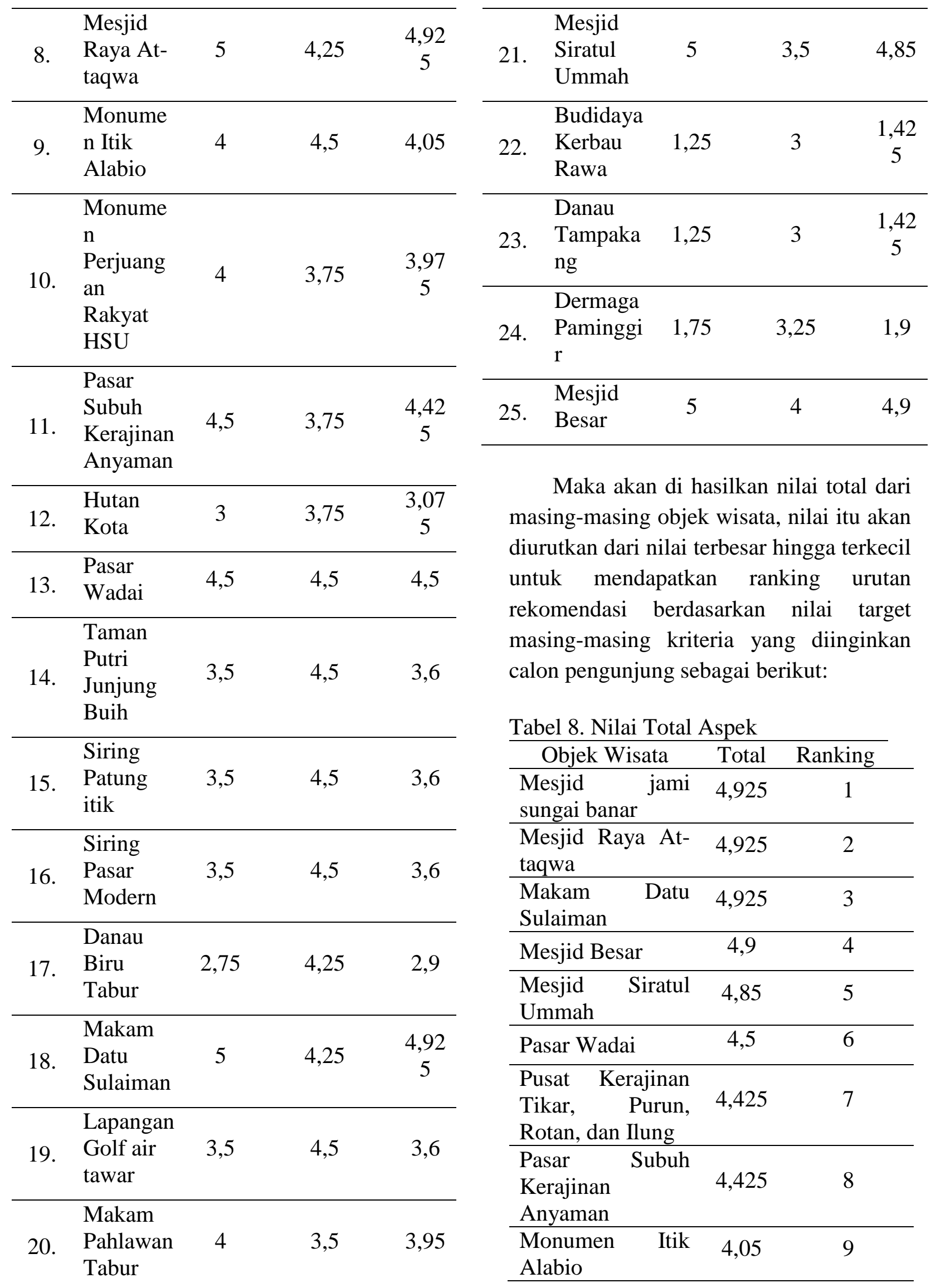




\begin{tabular}{|c|c|c|}
\hline $\begin{array}{l}\text { Monumen } \\
\text { Perjuangan } \\
\text { Rakyat HSU }\end{array}$ & 3,975 & 10 \\
\hline $\begin{array}{l}\text { Makam Pahlawan } \\
\text { Tabur }\end{array}$ & 3,95 & 11 \\
\hline Candi Agung & 3,825 & 12 \\
\hline $\begin{array}{l}\text { Taman Putri } \\
\text { Junjung Buih }\end{array}$ & 3,6 & 13 \\
\hline Siring Patung itik & 3,6 & 14 \\
\hline $\begin{array}{ll}\text { Siring } & \text { Pasar } \\
\text { Modern } & \end{array}$ & 3,6 & 15 \\
\hline $\begin{array}{l}\text { Lapangan Golf air } \\
\text { tawar }\end{array}$ & 3,6 & 16 \\
\hline $\begin{array}{lr}\text { Kolam } & \text { Renang } \\
\text { Tirta } & \text { Agung } \\
\text { Suryanata } & \\
\end{array}$ & 3,575 & 17 \\
\hline Danau Cermin & 3,15 & 18 \\
\hline Itik Alabio & 3,075 & 19 \\
\hline Hutan Kota & 3,075 & 20 \\
\hline Danau Biru Tabur & 2,9 & 21 \\
\hline $\begin{array}{l}\text { Melati } \\
\text { Waterboom }\end{array}$ & 2,025 & 22 \\
\hline $\begin{array}{l}\text { Dermaga } \\
\text { Paminggir }\end{array}$ & 1,9 & 23 \\
\hline $\begin{array}{l}\text { Budidaya Kerbau } \\
\text { Rawa }\end{array}$ & 1,425 & 24 \\
\hline $\begin{array}{l}\text { Danau } \\
\text { Tampakang }\end{array}$ & 1,425 & 25 \\
\hline
\end{tabular}

Setelah mendapatkan hasil ranking, maka sistem akan diuji menggunakan skala Likert skala likert adalah skala psikomentrik yang sangat umum dipakai dalam kuisioner, juga sering digunakan dalam riset untuk mengukur pendapat responden untuk menetukan tingkat akurasi. Nama skala likert ini diambil dari nama penciptanya yaitu Resis Liker (Darmadi, 2011).

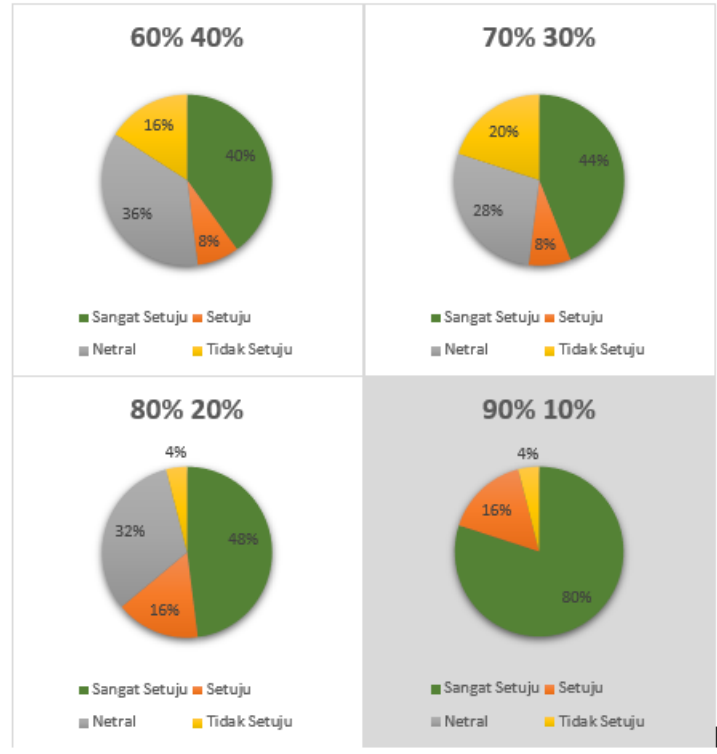

Gambar 3. Diagram Pengujian Sistem

Core factor $90 \%$ secondary factor $10 \%$

a. Responden yang menjawab sangat sesuai ada $80 \%$ atau 20 orang (skor 4 )

b. Responden yang menjawab sesuai ada $16 \%$ atau 4 orang (skor 3 )

c. Responden yang menjawab netral ada $0 \%$ atau 0 orang (skor 2 )

d. Responden yang menjawab tidak sesuai ada $4 \%$ atau 1 orang (skor 1 )

Dari data di atas maka akan mendapat hasil seperti ini:

Sangat sesuai $20 \times 4=80$

Sesuai 4 × $3=12$

Netral $0 \times 2=0$

Tidak Sesuai 1 x $1=1$

Setelah mendapatkan nilai dari masingmasing keterangan, lalu nilai itu dijumlahkan, maka hasil nya adalah 93. Penyelesaian:

Agar mendapatkan hasil interpretasi, maka harus diketahui dulu skor tertinggi dan skor terendah. 
Nilai Skor Tertinggi $=$ skor tertinggi likert $\mathrm{x}$ jumlah responden $=4 \times 25=100$

Nilai Skor Terendah $=$ skor terendah likert $\mathrm{x}$ jumlah responden $=1 \times 25=25$

ISP $=$ total skor / nilai skor tertinggi likert $\mathrm{x} 100$

$$
=93 / 100 \times 100
$$

$=93 \%$ berada dalam kategori "sangat sesuai".

Tampilan aplikasi yang telah dibuat berdasarkan analisa yang sudah dilakukan sebelumnya dapat dilihat pada Gambar 4.

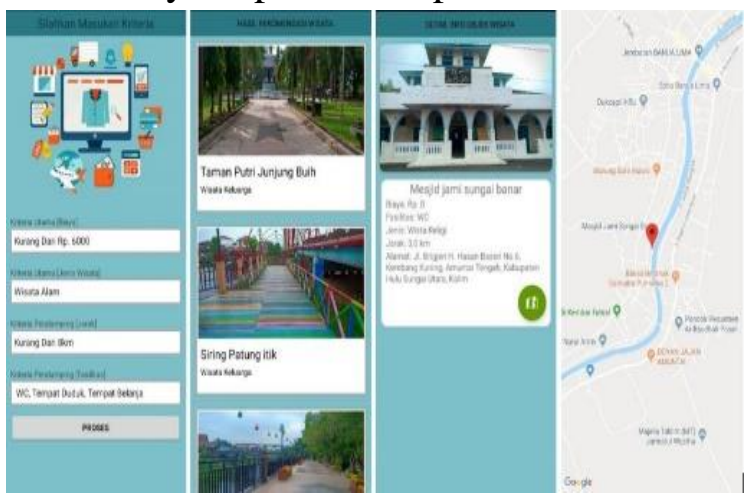

Gambar 4. Tampilan Aplikasi SPK

Bagian-bagiannya yaitu user akan membuka halaman fitur SPK untuk mengisi masing-masing kriteria berdasarkan objek wisata yang diinginkan. Setelah memasukkan data maka secara otomatis sistem akan menunjukkan rekomendasi objek wisata berdasarkan perankingan hasil profile matching.

\section{SIMPULAN DAN SARAN}

Sistem rekomendasi objek wisata ini telah berhasil diterapkan menggunakan dengan menggunakan metode profile matching dan mampu memberikan hasil rekomendasi objek wisata di Kabupaten HSU kepada wisatawan. Sistem ini dapat memberikan hasil rekomendasi objek wisata berdasarkan nilai kriteria yang ditentukan wisatawan berdasarkan kriteria yang diinginkan. Dari hasil Interpretasi Skor Perhitungan (ISP) dapat disimpulkan bahwa sistem ini sangat cocok untuk digunakan dalam merekomendasikan objek wisata yang ada di Kabupaten Hulu Sungai Utara dengan hasil ISP sebesar 93\%. Untuk kedepannya, sistem dapat ini bisa dikembangkan lagi dengan menggunakan metode recommender system terbaru sehingga dapat memberikan hasil yang lebih baik. Penambahan fitur rating dari masing-masing objek wisata yang langsung diisi oleh wisatawan yang telah mengunjungi obyek wisata tersebut juga dapat meningkatkan fungsi dari sistem rekomendasi dalam merekomendasikan obyek wisata bagi calon pengunjung berikutnya.

\section{DAFTAR PUSTAKA}

Afrianty, I., \& Umbara, R. (2016). Sistem Pendukung Keputusan (SPK) Menentukan Kelayakan Calon Penerima Zakat Menerapkan MultiFactor Evaluation Process (MFEP). Seminar Nasional Teknologi Informasi, Komunikasi Dan Industri (SNTIKI) 8, 11, 87-94.

Agustin, Y. H., \& Kurniawan, H. (2015). Sistem Pendukung Keputusan dalam Penilaian Kinerja Dosen Menggunakan Metode Weighted Product (Studi Kasus : Dosen STMIK Balikpapan). Seminar Nasional Informatika 2015, 1(1), 1-7.

Alkaff, M., Khatimi, H., Sari, Y., Darmawan, P., \& Primananda, R. (2019). Android Based Expert Sistem To Detect Types of Adhd. Jurnal Teknologi Informasi Dan Ilmu Komputer (JTIIK) Vol., 6(2), 135140. https://doi.org/10.25126/jtiik.201961 265

Badan Pusat Statistik Kabupaten Hulu Sungai Utara. (2016). Kabupaten 
Hulu Sungai Utara Dalam Angka.

Darmadi, H. (2011). Metode Penelitian Pendidikan. Alfabeta.

Dennis, A., Wixom, B. H., \& Tegarden. (2012). Systems Analysis dan Design (B. L. Golub (Ed.); Fourth Edi). Don Fowley.

Faturochman, G. N. (2019). Perancangan Sistem Pendukung Keputusan Pemilihan Tempat Wisata Tirta di Kota Bekasi Menggunakan Metode Profile Matching Berbasis Web.

Irianto. (2017). Pemilihan Perusahaan Jasa Pengiriman Barang Terbaik Menggunakan Metode Topsis. 1(3), 74-79.

Kementerian Keuangan. (2005). Direktorat Jenderal Perimbangan Keuangan. Kementerian Keuangan. http://www.djpk.kemenkeu.go.id/?pa ge_id=321

Muhaimin, F. Al, Widians, J. A., \& Cahyono, B. (2018). Sistem Pendukung Keputusan Pemilihan Obyek Wisata di Kota Balikpapan Menggunakan Metode Profile Matching. Jurnal Teknologi Informasi, 2(1), 90-96.

Pemerintah Kabupaten Hulu Sungai Utara. (2019). Lokasi Wisata - Pemerintah Kabupaten Hulu Sungai Utara. https://www.hulusungaiutarakab.go.i d/lokasi-wisata/

Perdana, N. G., \& Widodo, T. (2013). Sistem Pendukung Keputusan Pemberian Beasiswa Kepada Peserta Didik Baru Menggunakan Metode TOPSIS. Seminar Nasional Teknologi Informasi \& Komunikasi Dan Industri Terapan 2013 (SEMANTIK 2013), 3(11), 265-272.

Ramadani, W., Damanik, I. S., Tambunan, H. S., Bangsa Pematangsiantar, T., \& Stikom, D. (2019). Analisis Metode Profile Matching Dalam
Merekomendasikan Obyek Wisata di Kabupaten Simalungun. In Seminar Nasional Matematika dan Terapan (Vol. 1). Widyanti Ramadani. http://bulletin.indomsacehsumut.org/index.php/simantap/a rticle/view/97

S, S., Wijayanti, A. D., Sumarno, H., Priyono, H., \& Maulida, L. (2020). Penerapan Metode Profile Matching pada Pemilihan Guru Terbaik SMK Madani. J-SAKTI (Jurnal Sains Komputer Dan Informatika), 4(1), 179. https://doi.org/10.30645/jsakti.v4i1.197 